\title{
Tomographic Analysis and Modeling of Polymer Electrolyte Fuel Cell Unsupported Catalyst Layers
}

\author{
Hiroshi Ishikawa, ${ }^{1,2}$ Sebastian Henning, ${ }^{3, *}$ Juan Herranz, ${ }^{3, * *}$ Alexander Eychmüller, ${ }^{4}$ \\ Makoto Uchida, ${ }^{5, *, z}$ and Thomas J. Schmidt $\oplus^{3,6, * *}$ \\ ${ }^{1}$ Interdisciplinary Graduate School of Medicine and Engineering, University of Yamanashi, Kofu 400-8511, Japan \\ ${ }_{2}^{2}$ Panasonic Corporation, Moriguchi, Osaka 570-8501, Japan \\ ${ }^{3}$ Electrochemistry Laboratory, Paul Scherrer Institut, 5232 Villigen, Switzerland \\ ${ }^{4}$ Physical Chemistry, Technische Universität Dresden, 01062 Dresden, Germany \\ ${ }^{5}$ Fuel Cell Nanomaterials Center, University of Yamanashi, Kofu 400-0021, Japan \\ ${ }^{6}$ Laboratory of Physical Chemistry, ETH Zurich, 8093 Zurich, Switzerland
}

Polymer electrolyte fuel cells' (PEFCs) widespread commercialization is hindered by the devices' limited durability, in terms caused by the corrosion of the carbon support used in the Pt-based PEFC catalysts. Using unsupported electrocatalysts could mitigate such durability issues, but little is known regarding the manner in which their processing into catalyst layers (CLs) affects pore size distribution (PSD) and PEFC performance. Thus, we have used a computational model to investigate the modes of agglomerate packing in CLs made from unsupported $\mathrm{Pt}_{3} \mathrm{Ni}$ nanochain ensembles (aerogels) or Pt black, and complemented this analysis with focused ion beam scanning electron microscopy tomography of corresponding real CLs. 3D structures, PSDs and tortuosities were obtained for real and computed CLs and were found to be in good agreement. The Pt black CL mainly exhibits large and straight pores ( $>100 \mathrm{~nm}$ wide), while the $\mathrm{Pt}_{3} \mathrm{Ni}$ aerogel CL mostly features small and twisted pores $(<100 \mathrm{~nm}$ wide) that cause the significantly poorer $\mathrm{O}_{2}$ mass transport (vs. Pt black) observed in PEFC experiments. Moreover, this modeling approach leads to key insights on the working principle of a filler material used for positively shifting the average PSD and improving the PEFC performance of the $\mathrm{Pt}_{3} \mathrm{Ni} \mathrm{CL}$

(C) The Author(s) 2018. Published by ECS. This is an open access article distributed under the terms of the Creative Commons Attribution 4.0 License (CC BY, http://creativecommons.org/licenses/by/4.0/), which permits unrestricted reuse of the work in any medium, provided the original work is properly cited. [DOI: 10.1149/2.0371802jes]

(cc) BY

Manuscript submitted November 20, 2017; revised manuscript received December 24, 2017. Published January 4, 2018.

To foster the widespread commercialization of polymer electrolyte fuel cells (PEFCs), a great research effort is currently dedicated to reduce the cost of the latter devices by decreasing Pt catalyst loadings in the membrane electrode assemblies (MEAs) and by suppressing the voltage losses during the long-term operation through enhanced catalyst stability. ${ }^{1,2}$ In recent years, the catalyst's activity for the more Pt-demanding oxygen reduction reaction (ORR) has been drastically improved by alloying $\mathrm{Pt}$ with $\mathrm{Co}, \mathrm{Fe}$, or $\mathrm{Ni}^{3-5}$ and by controlling the catalyst shape and crystal facets; 6,7 therefore, the latest ORR-catalysts exhibit more than 20 times higher surface-specific ORR-activity (SA) than conventional $\mathrm{Pt}$ nanoparticles supported on carbon $(\mathrm{Pt} / \mathrm{C})$ when electrochemically tested in liquid electrolyte half cell tests. ${ }^{8}$ Furthermore, to prevent the voltage losses caused by carbon corrosion ${ }^{9,10}$ upon high potential conditions (up to $1.5 \mathrm{~V}$ ) encountered during fuel cell start-up/shut-down, graphitized-carbon supports ${ }^{11}$ (e.g. carbon nanotubes, carbon nanofibers ${ }^{12}$ ), non-carbon supports (e.g. conductive metal oxides ${ }^{13-15}$ ), extended surface catalysts (e.g. nanostructured thin films ${ }^{16}$ ), and unsupported catalysts (e.g. Pt nanowires, nanocapsules, nanochains ${ }^{17-20}$ ) have been studied.

Among these approaches, the latter use of unsupported catalysts has been proven to lead to MEAs with improved fuel cell durability over $\mathrm{Pt} / \mathrm{C},{ }^{21}$ but the fuel cell performance of such unsupported catalyst layers has seldom been assessed using application-relevant $\mathrm{H}_{2}$ and air as the reactant feed in actual PEFCs- a crucial aspect that could be problematic when using such unsupported materials, since these are expected to lead to significantly thinner CLs with potentially worse mass transport properties. Specifically, whereas cathodic CLs using a $\mathrm{Pt} / \mathrm{C}$ catalyst feature a thickness of $\approx 10-20 \mu \mathrm{m}$ (at loadings of $\approx 0.4 \mathrm{mg}_{\mathrm{Pt}} / \mathrm{cm}^{2}$ ), the thickness of CLs using unsupported catalysts at a comparable Pt-loading is typically much lower $(\approx 1-2$ $\mu \mathrm{m})$, because omitting the $\approx 10$-fold less dense carbon aggregates (vs. Pt alone) results in a significant volume loss of the whole catalyst layer. ${ }^{18}$ Consequently, micro-scale $\mathrm{O}_{2}$ diffusion resistance near the Pt surface (also known as the territory effect ${ }^{22-24}$ ) could increase drastically, negatively impacting the CL's mass transport and high

\footnotetext{
*Electrochemical Society Student Member.

***Eectrochemical Society Member.

${ }^{\text {zE} E-m a i l: ~ u c h i d a m @ y a m a n a s h i . a c . j p ~}$
}

current performance. Thus, to improve $\mathrm{O}_{2}$ diffusivity in CLs from unsupported catalysts, it is necessary to design both catalyst shapeand pore-structures, as well as to understand the underlying structure formation mechanism during catalyst layer preparation. ${ }^{25}$

In this respect, we have recently reported on the $\mathrm{O}_{2}$-diffusion issues discussed above upon testing an unsupported $\mathrm{Pt}_{3} \mathrm{Ni}$ alloy aerogel catalyst consisting of a 3D nanochain network in a differential fuel cell. ${ }^{26}$ Initially, the $\mathrm{Pt}_{3} \mathrm{Ni}$ aerogel MEA displayed a high current density performance significantly poorer than that of $\mathrm{Pt} / \mathrm{C}$ under $\mathrm{H}_{2}$ /air operation. From the overvoltage analysis in the high current density region, the voltage loss was mainly related to $\mathrm{O}_{2}$ diffusion resistance rather than $\mathrm{H}^{+}$conduction resistance or ORR kinetic losses (cf. Ref. 26. Figure S3 in the Supplementary Information, whereby the proton resistance along the ultra-thin aerogel CL is shown to be negligible). Subsequently, this performance shortcoming was successfully mitigated by the addition of a filler material $\left(\mathrm{K}_{2} \mathrm{CO}_{3}\right)$ to the initial catalyst ink that, after membrane spraying and drying, was acid-washed from the CL before the actual PEFC test and positively shifted its overall porosity and pore size distribution. While this finding highlights the special importance of optimizing the CL structure when using unsupported catalysts to reach sufficient $\mathrm{O}_{2}$-diffusivity, a deeper understanding of the mechanisms leading to this performance improvement could help to render such strategies extensible to other unsupported nanoparticle systems.

To allow such investigations of the CL structure, focused ion beam scanning electron microscopy (FIB-SEM) and subsequent image processing has been intensively developed in recent years. ${ }^{27-29}$ By segmenting and stacking SEM images of CL slices, 3D structures can be reconstructed and their structural properties (e.g. pore size distributions (PSDs) and pore/solid tortuosity) can be numerically analyzed. Furthermore, to theoretically investigate the CL structure formation process, computational modeling studies have recently been performed. ${ }^{30-36}$ Inoue et al., for instance, designed model aggregates by applying pseudo inter-particle forces among the model particles $;^{37}$ by tuning the probability density function, aggregate shapes could be controlled (e.g. ball-type or bar-type aggregates) to mimic the actual shapes observed in transmission electron microscopy (TEM) images. Next, by packing multiple aggregates in an analysis domain, model CLs were constructed and their structural properties were analyzed 
and compared with those of real CLs. The great advantage of this modeling approach is not only that it is able to mimic actual catalyst shapes and to simulate real CLs, but also that it can be used to carry out studies on CLs which are actually difficult to form or analyze experimentally. ${ }^{38,39}$ Furthermore, by modeling the structure formation process, the effects of catalyst shape (and, when applicable, filler materials - cf. below) on the CL structure can be investigated.

With this motivation and combining experimental and modeling tools, in the first part of the present work CLs of unsupported Pt black and $\mathrm{Pt}_{3} \mathrm{Ni}$ aerogel (with 'nanoblock' vs. 'nanochain' shapes, respectively), were analyzed applying FIB-SEM tomography and computational modeling. The model CLs were constructed using aggregates designed to mimic the shapes in corresponding TEM images. 3D images, cross-sectional images, PSDs and tortuosities of the model CLs were obtained and compared to those of real layers analyzed by FIBSEM followed by image processing. Subsequently, the second part of this study presents a modeling approach to investigate the effect of the previously mentioned filler material $\left(\mathrm{K}_{2} \mathrm{CO}_{3}\right)$ on the final catalyst layer structure, considering the experimental observation in Ref. 26 that this $\mathrm{K}_{2} \mathrm{CO}_{3}$ cannot be resolved in cross-section SEM images of the CL, even if EDX elemental maps points at its homogeneous distribution along the latter. Again, images and structural properties of the model CLs derived for this purpose were compared with data of real catalyst layers of $\mathrm{Pt}_{3} \mathrm{Ni}$ plus $\mathrm{K}_{2} \mathrm{CO}_{3}$, as to evaluate the validity of the models' hypotheses and to increase the understanding of the carbonate's role on the CLs' properties. Finally, the interplay between particle shapes, CL structures, $\mathrm{O}_{2}$ diffusivity in the CLs and cell performance is discussed in the context of the findings in these two sections.

\section{Experimental}

Real CL fabrication.-For the FIB-SEM measurement and the structural analysis of real catalyst layers, three CLs using Pt black, $\mathrm{Pt}_{3} \mathrm{Ni}$ aerogel, and $\mathrm{Pt}_{3} \mathrm{Ni}$ aerogel plus $\mathrm{K}_{2} \mathrm{CO}_{3}$ were fabricated as follows. Firstly, catalyst inks of Pt black (HiSPEC 1000, Johnson Matthey) were prepared by mixing $50 \mathrm{mg}$ of catalyst, $240 \mathrm{mg}$ of Nafion solution (Nafion $1100 \mathrm{EW}, 5 \mathrm{wt} \%$, Sigma Aldrich, for a Nafion-tocatalyst mass ratio (NCR) of 0.12 ) and $3 \mathrm{ml}$ of a $8 \mathrm{wt} \%$ aqueous isopropanol (IPA) solution (IPA 99.9\%, Chromasolv Plus for HPLC, Sigma Aldrich and ultrapure water, $18.2 \mathrm{M} \Omega \mathrm{cm}$ ). Catalyst inks of $\mathrm{Pt}_{3} \mathrm{Ni}$ aerogel (synthesized according to the method described in our previous work ${ }^{40}$ ) with and without $\mathrm{K}_{2} \mathrm{CO}_{3}$ were prepared according to the procedures described in our previous report ${ }^{26}$ by mixing $5 \mathrm{mg}$ of catalyst, $0.7 \mathrm{mg}$ of $\mathrm{K}_{2} \mathrm{CO}_{3}(99.995 \%$ trace metals basis, Sigma Aldrich), $18 \mathrm{mg}$ of $\mathrm{Na}^{+}$-exchanged Nafion solution (prepared from a 1:2 mixture of $0.1 \mathrm{M} \mathrm{NaOH}$ and Nafion solution, and equal to a NCR of 0.12 ) and $1.0 \mathrm{ml}$ of an $8 \mathrm{wt} \%$ aqueous isopropanol solution. The amount of $\mathrm{K}_{2} \mathrm{CO}_{3}$ was set to an optimized value of $m_{\mathrm{K} 2 \mathrm{CO} 3} / m_{\mathrm{Pt} 3 \mathrm{Ni}}$ $=0.14\left(\mathrm{~K}_{2} \mathrm{CO}_{3}\right.$ to catalyst weight ratio, KCR), where $m_{\mathrm{K} 2 \mathrm{CO} 3}$ and $m_{\mathrm{Pt} 3 \mathrm{Ni}}$ are the masses of $\mathrm{K}_{2} \mathrm{CO}_{3}$ and $\mathrm{Pt}_{3} \mathrm{Ni}$ aerogel, respectively (see Reference 26 for details about KCR optimization). Next, after ultrasonication (USC100T, $45 \mathrm{kHz}$, VWR) for 30 minutes, the catalyst inks of $\mathrm{Pt}$ black, $\mathrm{Pt}_{3} \mathrm{Ni}$ aerogel and $\mathrm{Pt}_{3} \mathrm{Ni}$ aerogel plus $\mathrm{K}_{2} \mathrm{CO}_{3}$ were sprayed onto a pre-cut piece of Nafion XL 100 membrane (DuPont) to obtain loadings between 0.3 and $0.4 \mathrm{mg}_{\mathrm{Pt}} \mathrm{cm}^{-2}$. FIB-SEM samples were prepared by spraying onto conductive GDL substrates (Sigracet 25 BC, SGL Group) to facilitate the electron microscopy analysis. When applicable, the $\mathrm{K}_{2} \mathrm{CO}_{3}$ filler in the $\mathrm{Pt}_{3} \mathrm{Ni}$ aerogel plus $\mathrm{K}_{2} \mathrm{CO}_{3}$ samples was removed by immersing the dried catalyst-coated membrane into $1 \mathrm{M} \mathrm{H}_{2} \mathrm{SO}_{4}$ solution (96\%, Suprapur, Merck) overnight ( $\approx 16$ hours), followed by rinsing with ultrapure water and drying under ambient conditions.

Cell performance tests.-MEAs were fabricated by hotpressing the catalyst coated membranes at $120^{\circ} \mathrm{C}$ and $1 \mathrm{bar} / \mathrm{cm}^{2}$ geom for 5 minutes to a gas diffusion layer (GDL $25 \mathrm{BC}$, Sigracet) and a commercial gas diffusion electrode (Johnson Matthey, $0.4 \mathrm{mg}_{\mathrm{Pt}_{\mathrm{t}}} / \mathrm{cm}^{2}$ geom HISPEC $9100 \mathrm{Pt} / \mathrm{HAS}$ on Sigracet GDL 25 BC) on the cathode and anode side, respectively. The differential PEFC used for this study was developed in house and features 5 parallel channels of $1 \mathrm{~mm}$ width over an active area of $1 \mathrm{~cm}^{2} .{ }^{41}$ Following cell break in, current vs. potential $(\mathrm{i}-\mathrm{V})$ polarization curves were recorded at $80^{\circ} \mathrm{C}$ and $100 \% \mathrm{RH}$ with $\mathrm{H}_{2}$ anode/ air cathode flow rates of $300 / 750 \mathrm{ml} / \mathrm{min}$ (stoichiometries $\geq 30 / \geq 30$ ) at 1.5 bar $_{\text {abs }}$, using a Biologic VSP-300 potentiostat with a $10 \mathrm{~A} / 5 \mathrm{~V}$ current booster. SAs were extracted at 0.9 $\mathrm{V}$ from corresponding $\mathrm{H}_{2} / \mathrm{O}_{2}$ polarization curves after correction for the cell resistance. Electrochemical surface area (ECSA) values were averaged from double-layer corrected $\mathrm{H}$-adsorption and $\mathrm{H}$-desorption charges between 0.09 and $0.4 \mathrm{~V}$ (conversion factor of $\left.210 \mu \mathrm{C} / \mathrm{cm}^{2}\right)^{42}$ in cyclic voltammograms recorded at $25^{\circ} \mathrm{C}, 100 \% \mathrm{RH}$ between 0.075 and $1.0 \mathrm{~V}$ at $50 \mathrm{mVs}^{-1}$ with $\mathrm{a} \mathrm{H}_{2}$ anode flow rate of $50 \mathrm{ml} / \mathrm{min}$ and the $\mathrm{N}_{2}$ cathode flow halted just prior to the measurement.

CL analysis using FIB-SEM.-FIB-SEM measurements were conducted according to the method described in our previous work. ${ }^{26}$ The FIB-SEM samples were cut into a rectangular shape $(5 \mathrm{~mm} \times 5$ $\mathrm{mm}$ ) by a scalpel and attached to a SEM sample holder using conductive carbon tape and silver glue. Prior to the FIB cutting, the area around the cross section was covered with a smooth carbon layer (thickness $\geq 0.5 \mu \mathrm{m}$ ) to minimize curtain effects. ${ }^{43}$ While slicing the CLs in $5 \mathrm{~nm}$ intervals with the focused ion beam, SEM images with an $\mathrm{x}$ - and y resolution of $4 \mathrm{~nm} /$ pixel were captured continuously. To improve the image segmentation accuracy during the CL reconstruction process, both secondary electron (SE) images and energy-selective backscattered electron (EsB) images were recorded.

SEM image processing and $C L$ reconstruction.-MATLAB and its image processing toolbox (R2015a, Mathworks Inc.) were used for SEM image processing and $3 \mathrm{D}$ reconstruction. The image processing algorithm was described elsewhere. ${ }^{29}$ First, the xy position of each SEM image was properly aligned to correct for image drifting. Subsequently, a representative region of the CL structure was selected and the images were cropped to $1 \mu \mathrm{m} \times 1 \mu \mathrm{m}$. Next, for image segmentation, a composite image was obtained by combining the SE and EsB image of the same cross section to reduce edge effects and identify pore and solid more accurately. Furthermore, by applying contrast and noise filters, image contrast was enhanced and dot noise was removed. After image processing, the composite images were segmented into pore and solid by setting the brightness threshold manually based on visual inspection. Finally, by stacking segmented SEM images in the z-direction, $1 \mu \mathrm{m}$ cubic structures were obtained.

Procedure of CL modeling.-Model CLs simulating the real CL from $\mathrm{Pt}$ black and $\mathrm{Pt}_{3} \mathrm{Ni}$ aerogel were constructed by the following procedure. In the first step, model aggregates and agglomerates of $\mathrm{Pt}$ black and $\mathrm{Pt}_{3} \mathrm{Ni}$ aerogels were designed by mimicking the actual particle shapes of the catalysts based on TEM images (cf. below). For Pt black and $\mathrm{Pt}_{3} \mathrm{Ni}$ aerogel modeling, ball-type aggregates consisting of 25 particles ( $8 \mathrm{~nm}$ in diameter) and bar-type aggregates consisting of 25 particles ( $6 \mathrm{~nm}$ in diameter) were prepared at a space resolution of 2 $\mathrm{nm}$. In the modeling algorithm, the ball-type and bar-type aggregates were simulated by applying pseudo-attractive and pseudo-repulsive forces between each pair of particles based on a probability density function. ${ }^{37}$ Furthermore, by applying a random factor to the connecting particle position, 100 types of similar aggregates were prepared for each material. The overlap fraction between the particles was set to $20 \pm 2$ vol. \%, which yielded the best agreement with the observation from TEM images (cf. below). Next, 100 types of ball-and bar-type agglomerates were formed by connecting 50 randomly chosen ball or bar aggregates, respectively. The overlap fraction of the aggregates was set to $10 \pm 5$ vol. $\%$, again based on the visual inspection of the TEM images.

To model the complete CL structure, an analysis domain (AD) of 1 $\mu \mathrm{m}$ in width $\times 1 \mu \mathrm{m}$ in depth $\times 2 \mu \mathrm{m}$ in height at a space resolution of $2 \mathrm{~nm}$ was defined, whereby the lower half $(1 \mu \mathrm{m} \times 1 \mu \mathrm{m} \times 1 \mu \mathrm{m})$ was used for the structure comparison to real CLs. First, Pt structures of the model CLs were constructed by accumulating the ball agglomerates 
Table I. Real CL properties and modeling condition.

\begin{tabular}{|c|c|c|c|c|c|c|c|}
\hline \multirow[b]{2}{*}{ CL properties } & \multirow[b]{2}{*}{ Agglomerate shape } & \multirow[b]{2}{*}{$\begin{array}{l}\text { Pt particle size } \\
\mathrm{nm}\end{array}$} & \multicolumn{3}{|c|}{ Volume fraction } & \multirow[b]{2}{*}{$\begin{array}{c}\text { Porosity } \\
(\%)\end{array}$} & \multirow[b]{2}{*}{$\begin{array}{c}\text { Overlap fraction } \\
(\%)\end{array}$} \\
\hline & & & $\begin{array}{l}\mathrm{Pt} \\
(\%)\end{array}$ & $\begin{array}{c}\mathrm{K}_{2} \mathrm{CO}_{3} \\
(\%)\end{array}$ & $\begin{array}{c}\text { Ionomer } \\
(\%)\end{array}$ & & \\
\hline Pt black & balls (TEM) & 8 & $20^{1}$ & - & $25^{1}$ & $55^{2}$ & - \\
\hline $\mathrm{Pt}_{3} \mathrm{Ni}$ aerogels & bars (TEM) & 6 & $19^{1}$ & - & $21^{1}$ & $61^{2}$ & - \\
\hline $\mathrm{Pt}_{3} \mathrm{Ni}+\mathrm{K}_{2} \mathrm{CO}_{3}$ & bars (TEM) & 6 & $21^{1}$ & $19^{1}$ & $23^{1}$ & $62^{2}$ & - \\
\hline Model 1 (balls) & 50 balls & 8 & $19^{3}$ & - & $26^{3}$ & $55^{4}$ & $6^{5}$ \\
\hline Model 2 (bars) & 50 bars & 6 & $19^{3}$ & - & $22^{3}$ & $59^{4}$ & $7^{5}$ \\
\hline Model 3 (TFM) & 50 bars $+2 \mathrm{~nm}$ film & 6 & $17^{3}$ & $19^{3}$ & $21^{3}$ & $62^{4}$ & $10^{5}$ \\
\hline Model 4 (HAM) & 500 bars & 6 & $18^{3}$ & - & $21^{3}$ & $61^{4}$ & $5^{5}$ \\
\hline
\end{tabular}

and bar agglomerates in the $\mathrm{AD}$ from bottom to top. The accumulating process described above mimics the spray coating process used in the fabrication of real CLs. Ball and bar agglomerates were accumulated until the agglomerates reached the top of the AD $(2 \mu \mathrm{m})$. Overlap fractions between the agglomerates were adjusted to 6 vol. \% (Pt black) and 7 vol. \% ( $\mathrm{Pt}_{3} \mathrm{Ni}$ aerogel) to let the $\mathrm{Pt}$ volume fraction come close to the value obtained for real CL porosities (cf. Table I). The volume fractions of catalyst and ionomer were calculated from the FIB-SEM tomography porosity $(\rho)$, solid fraction (1- $\rho)$, NCR of 0.12 in the catalyst ink, and the $\mathrm{Pt}, \mathrm{Pt}_{3} \mathrm{Ni}$, and Nafion densities of 21500 , 19100 , and $1980 \mathrm{~kg} \mathrm{~m}^{-3}$, respectively. Next, ionomer was coated on the surface of the Pt structure. The ionomer coating approach was in accordance with the ionomer pocket model applied in References 37,44 , and 45, which takes into account ionomer adhesion-related processes such as solvent evaporation, generation of capillary forces, and binding effect. Ionomer was coated until the volume fraction of ionomer reached the set value $(\mathrm{NCR}=0.12)$ listed in Table I. Finally, the top half of the ADs was removed and $1 \mu \mathrm{m}^{3}$ cubic CL structures of ball model and bar model were obtained.

The construction of model CLs including $\mathrm{K}_{2} \mathrm{CO}_{3}$ as a filler was completed following two different approaches (see Results and discussion section for details). In the so-called "thin film model" (TFM) we assumed that $\mathrm{K}_{2} \mathrm{CO}_{3}$ forms a $2 \mathrm{~nm}$-thin film on the surface of $\mathrm{Pt}_{3} \mathrm{Ni}$, whereby the film thickness was set based on the $\mathrm{K}_{2} \mathrm{CO}_{3}$ volume fraction calculated from the KCR value of 0.14 in the catalyst ink (see above) and $\mathrm{Pt}_{3} \mathrm{Ni}$ and $\mathrm{K}_{2} \mathrm{CO}_{3}$ densities of 19100 and 2430 $\mathrm{kg} \mathrm{m}^{-3}$, respectively. The assumption that $\mathrm{K}_{2} \mathrm{CO}_{3}$ is homogeneously distributed in the form of a thin film is based on the findings in reference 26; in that work it was shown that $\mathrm{K}_{2} \mathrm{CO}_{3}$ dissolves completely in the catalyst ink, yet in the dried CLs both cross section SEM images and elemental mapping did not reveal any $\mathrm{K}_{2} \mathrm{CO}_{3}$ accumulation. The agglomerates coated with the thin film were accumulated in the same way as in the ball and bar models discussed above. The overlap fraction of the agglomerates including $\mathrm{K}_{2} \mathrm{CO}_{3}$ was set to $10 \mathrm{vol}$. \%, as to let the model CL porosity come close to the porosity of the real CL obtained by FIB-SEM tomography. After such $\mathrm{Pt}_{3} \mathrm{Ni}$ structures with $\mathrm{K}_{2} \mathrm{CO}_{3}$ were constructed, the $\mathrm{K}_{2} \mathrm{CO}_{3}$ film was removed to simulate the acid washing process in the real CL fabrication. Finally, ionomer was coated until the volume fraction of ionomer reached the set experimental value $(\mathrm{NCR}=0.12)$ using the same coating model mentioned above. Implicitly, for this model it was assumed that $\mathrm{K}_{2} \mathrm{CO}_{3}$ would cover the catalyst surface first, followed by the coating with Nafion ionomer. This was motivated by a recent study ${ }^{46}$ suggesting that Nafion coats the catalyst surface at a later stage of solvent evaporation, and to obtain a simple model compatible with our current modelling capabilities. Naturally, it is well imaginable for $\mathrm{K}_{2} \mathrm{CO}_{3}$ crystallization and Nafion coating to occur simultaneously during the drying process; however, modeling solvent evaporation ${ }^{46}$ and further material interactions remains beyond the scope of this work.

In the second, "huge agglomerate model" (HAM), we assumed that larger agglomerates of $\mathrm{Pt}_{3} \mathrm{Ni}$ aerogel are formed in the catalyst ink due to the increase in the solids-to-liquid ratio caused by the inclusion of $\mathrm{K}_{2} \mathrm{CO}_{3}$ without further ink dilution (see Real CL Fabrication section above). Hence, the model CL was composed of huge agglomerates of bars, assuming that they consisted of 10 bar agglomerates at an overlap fraction of 5 vol. \%. Again, 100 of these huge agglomerates were prepared with the same algorithm, and the CL structure was subsequently constructed by accumulation of these huge agglomerates. The overlap fraction was set to $5 \mathrm{vol}$. \%, again as to let the porosity come close to the value of the real CL obtained by FIB-SEM tomography. Subsequently, ionomer was coated until the volume fraction of ionomer reached the set experimental value $(\mathrm{NCR}=0.12)$ listed in Table I.

CL characterization.-On the basis of the $1 \mu \mathrm{m}^{3}$ cubic 3D structures of real and model CLs, PSDs and tortuosities of pore and solid were derived using Visual Studio Express 2013 (Microsoft) and programing codes developed elsewhere. ${ }^{47,48}$ The PSDs were calculated by the virtual sphere packing method and the tortuosities of pore and solid were calculated by the random walk method.

\section{Results and Discussion}

Relationship between catalyst shape and CL structure for Pt black and $\mathrm{Pt}_{3}$ Ni aerogel.-Fig. 1 shows TEM images of Pt black and $\mathrm{Pt}_{3} \mathrm{Ni}$ aerogel and the corresponding ball-type and bar-type model aggregates and agglomerates. Upon qualitative comparison, size and shape of the modeled ball and bar agglomerates are very similar to those on the TEM images of $\mathrm{Pt}$ black and $\mathrm{Pt}_{3} \mathrm{Ni}$ aerogel. Both real $\mathrm{Pt}_{3} \mathrm{Ni}$ aerogel and bar agglomerates display small pores between the aggregates and look sparser than Pt black catalyst and ball agglomerates. Additionally, Fig. 2 shows the CL structure modeling process using the ball and bar agglomerates of Fig. 1 (see Procedure of CL modeling above). Model CLs were constructed by accumulating model agglomerates (Figs. 2A, 2B, 2E, and 2F) and coating the ionomer (Figs. 2C and 2G, whereby the ionomer appears colored in green) until the set volume fractions were reached (cf. Table I). To compare the structures of model CLs with real CLs, both Pt and ionomer structure were combined and shown as solid (Figs. 2D and 2H-gray). In addition to the Pt structure, ionomer distributions between ball model and bar model differed from each other. The ionomer coating thickness in the bar model appears lower than in the ball model which can be attributed to the presence of small pores among bar agglomerates as mentioned above, resulting in higher Pt surface area and less ionomer agglomeration. 


\section{Pt black}
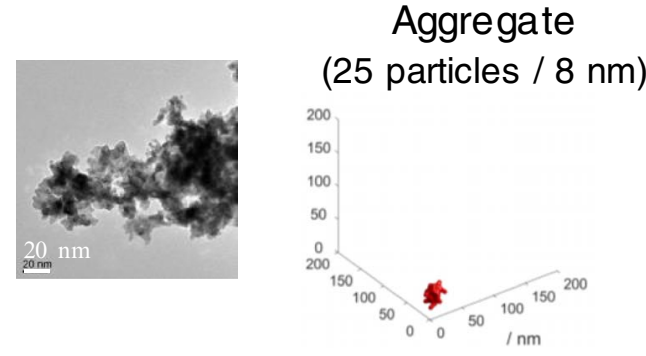

\section{Ball model}

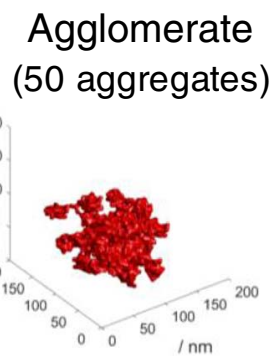

Figure 1. TEM images of $\mathrm{Pt}$ black and $\mathrm{Pt}_{3} \mathrm{Ni}$ aerogel and balltype and bar-type model aggregate and agglomerate.

\section{$\mathrm{Pt}_{3} \mathrm{Ni}$ aerogel}

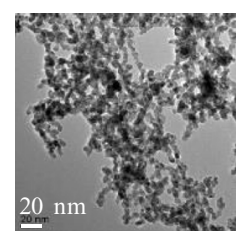

\section{Bar model}

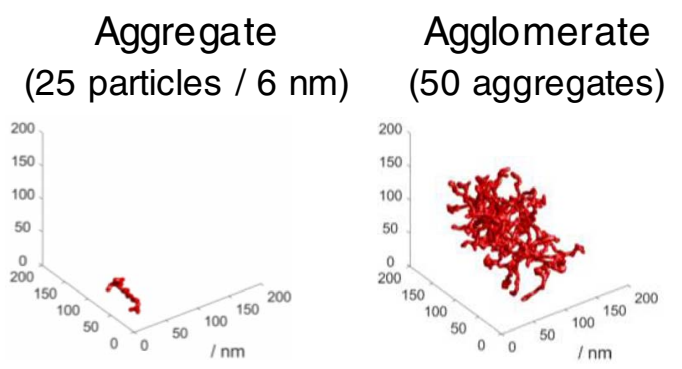

Next, Fig. 3 shows the 3D reconstruction and cross section images of real and model CLs; ball and bar model 3D and cross section images (Figs. $3 \mathrm{C}$ and $3 \mathrm{D}$ vs. $3 \mathrm{G}$ and $3 \mathrm{H}$, respectively) look very similar to those of the real CLs from Pt black (Figs. 3A and 3E) and $\mathrm{Pt}_{3} \mathrm{Ni}$ aerogel (Figs. 3B and $3 \mathrm{~F}$ ). Based on the 3D reconstructions, PSDs and tortuosities were calculated (for details see experimental information) and appear summarized in Fig. 4. The results of the PSD analysis were displayed using $\mathrm{dV} / \mathrm{d}(\log (\mathrm{D})$ plots as it is customarily used in the mercury porosimetry analysis for wide range PSDs (1 $\mathrm{nm}-1 \mu \mathrm{m})$. On the other hand, when focusing on the narrow PSD range between $1 \mathrm{~nm}$ and $200 \mathrm{~nm}$ (cf. inserts in Figs. 4A-4C), V plots were used following the approach of $\mathrm{N}_{2}$ adsorption analysis that emphasizes a pore size regime. The PSDs in Figs. 4A and 4C illustrate that the Pt black CL and the corresponding ball model mainly contain pores of widths $>100 \mathrm{~nm}$, while the $\mathrm{Pt}_{3} \mathrm{Ni}$ aerogel CL and the respective bar model predominantly feature pores $<100 \mathrm{~nm}$ wide. The formation of large pores in the ball model is likely related to the steric hindrance among the compact ball agglomerates during the accumulation process (Figs. 3C and 3G). In the bar model, on the other hand, the high aspect ratio of the aggregates leads to the formation of numerous small pores (primary pores ${ }^{49,50}$ within the bar agglomerates), somewhat preventing the formation of large pores (secondary pores among the bar agglomerates) in the CL (Figs. 3F and $3 \mathrm{H})$ - partly because the large pores were occupied by the various nanochain aggregates that protruded from the bar agglomerates. The difference at small pore diameters between the PSDs of the real $\mathrm{Pt}_{3} \mathrm{Ni}$

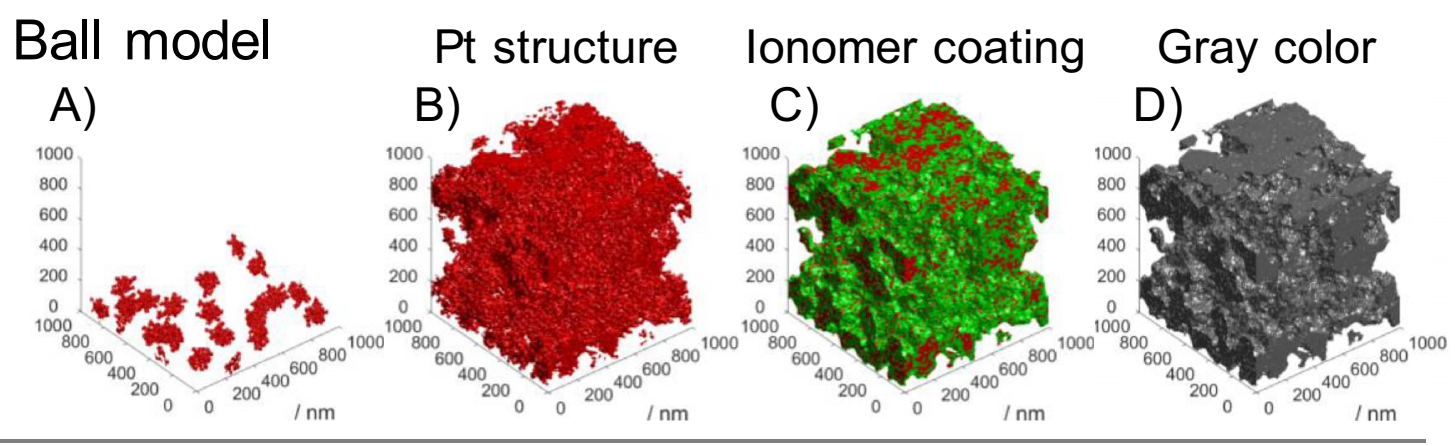

\section{Bar model}
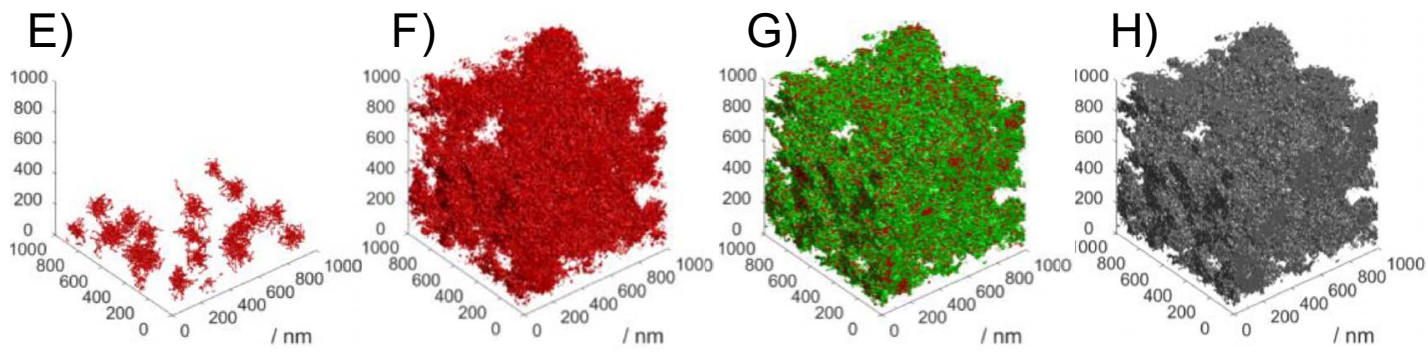

Figure 2. Modeling of the CL structures consisting of ball-type and bar-type agglomerates. 


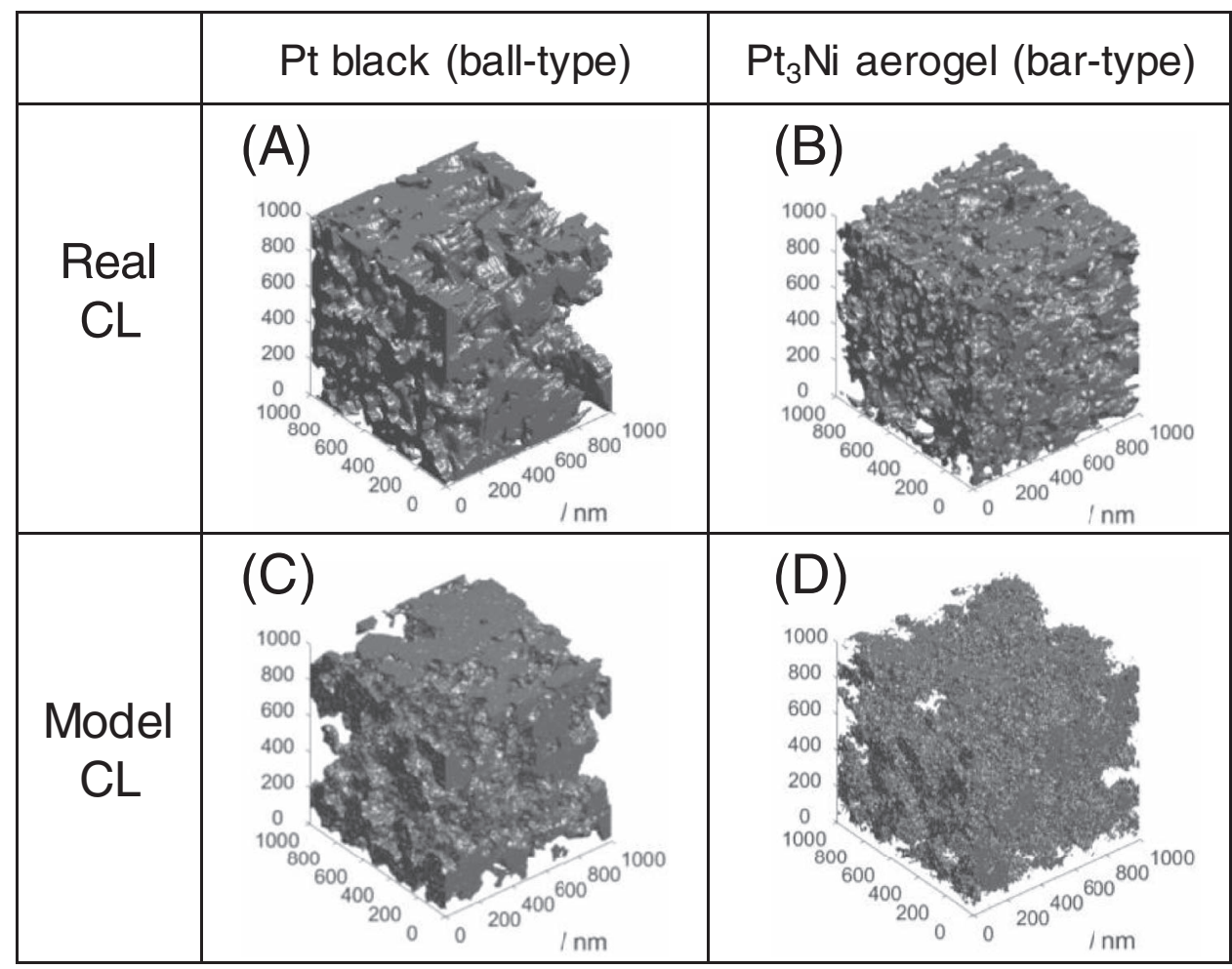

\begin{tabular}{|c|c|c|}
\hline & Pt black (ball-type) & $\mathrm{Pt}_{3} \mathrm{Ni}$ aerogel (bar-type) \\
\hline $\begin{array}{l}\text { Real } \\
\text { CL }\end{array}$ & 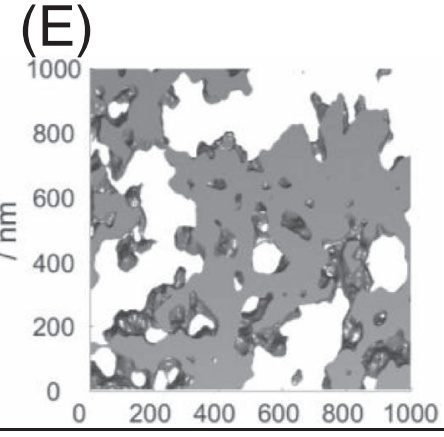 & 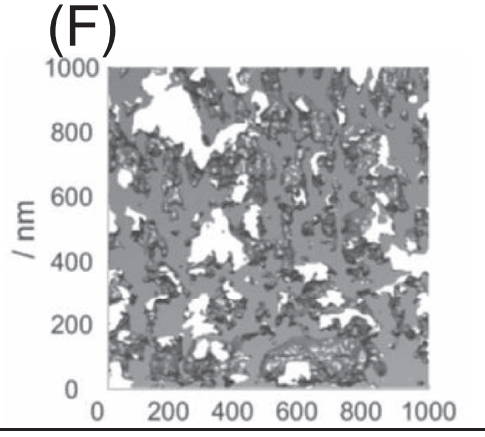 \\
\hline $\begin{array}{c}\text { Model } \\
\text { CL }\end{array}$ & $\begin{array}{cccc}(\mathrm{G}) \\
\\
4000\end{array}$ & 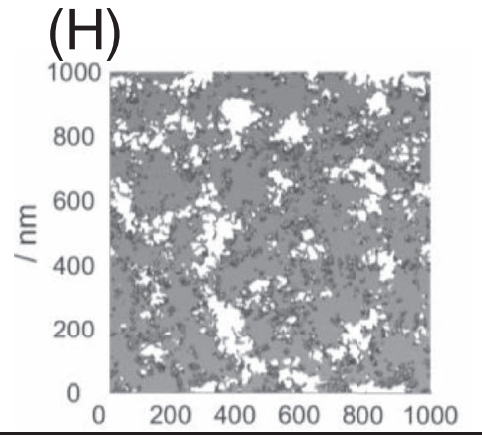 \\
\hline
\end{tabular}

Figure 3. Real CL structures using Pt black (A) and $\mathrm{Pt}_{3} \mathrm{Ni}$ aerogel (B) and model CL structures consisting of ball agglomerates (C) and bar agglomerates (D), and the cross-sectional images of each CL (E,F,G,H).

aerogel CL and the corresponding bar model might be attributed to the limited analysis accuracy of FIB-SEM tomography at such small feature sizes $(<50 \mathrm{~nm})$. In general, during CL cutting in FIB-SEM measurements, the ion beam can damage the CL structure to a certain extent, which will be particularly harmful for delicate nanostructures like the nanochains in the $\mathrm{Pt}_{3} \mathrm{Ni}$ aerogel. Furthermore, during image processing, small pores ( $<20 \mathrm{~nm}$ wide) could be mistakenly identified as noise by the applied noise filter.

Next, to investigate the connectivity of pore and solid structures in the CLs, their corresponding tortuosities were analyzed and compared for both CLs (Figs. 4B and 4D), whereby straight pore/solid structures correspond to a tortuosity value of 1 , and twisted pore/solid structures 
(A)
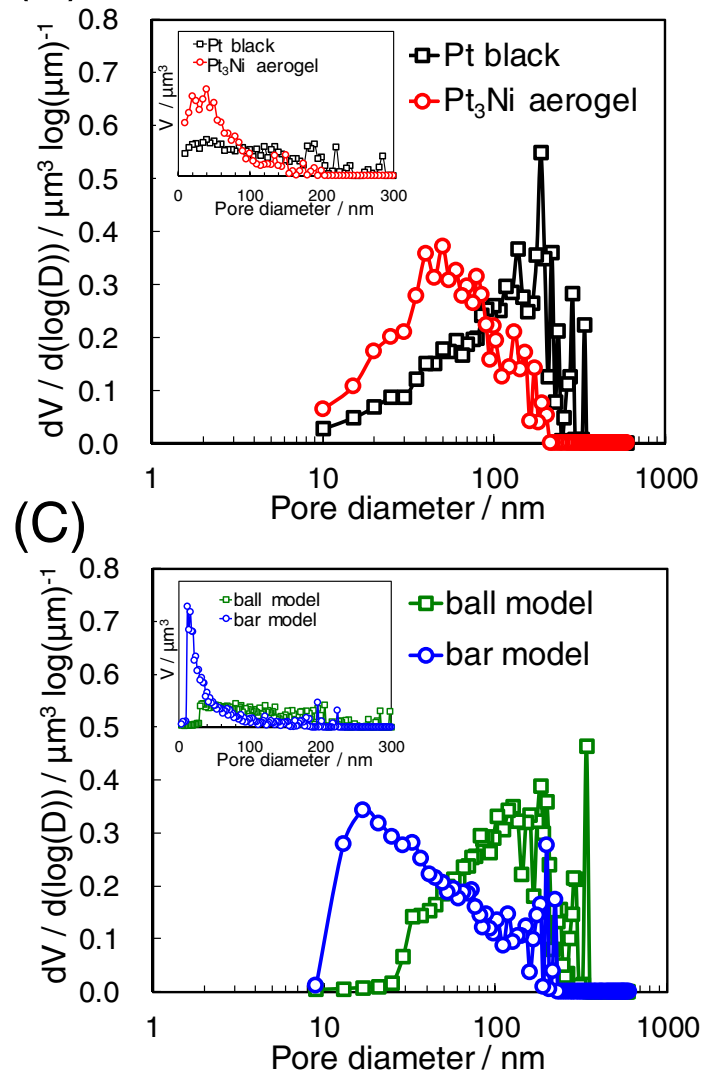
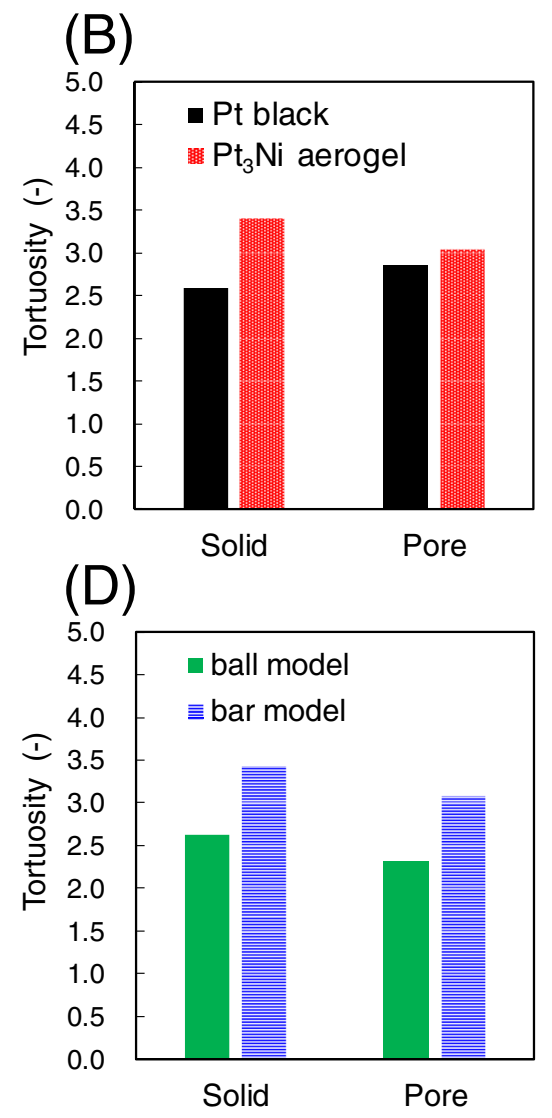

Figure 4. PSDs and tortuosities of the real CLs consisting of Pt black and $\mathrm{Pt}_{3} \mathrm{Ni}$ aerogel $(\mathrm{A}, \mathrm{B})$ and the model CLs consisting of ball agglomerates and bar agglomerates (C,D).

exhibit higher tortuosity values. Both pore and solid tortuosity of the $\mathrm{Pt}_{3} \mathrm{Ni}$ aerogel real $\mathrm{CL}$ and corresponding bar model were higher than those of the CLs made from Pt black and its complementing ball model. This difference is also discernable in the cross section images of the model CLs in Figs. 3G and 3H, and is probably caused by the high aspect ratio of the bar type aggregates, that translates into agglomerates with lower solid density. Concomitantly, the pore tortuosity of the bar model exceeded the one of the ball model due to the same reason.

The PSDs and pore tortuosity values of the CL significantly influence the $\mathrm{O}_{2}$ diffusivity in the CLs and the cell performances as illustrated by the $\mathrm{H}_{2}$ /air polarization curves in Fig. 5. Since the PEFC potential at high current densities can be regarded as a proxy for mass transport efficiency due to strong $\mathrm{O}_{2}$-concentration gradients, the significantly lower performance of $\mathrm{Pt}_{3} \mathrm{Ni}$ aerogel vs. Pt black electrodes proves the beneficial effect of the latter CLs' low solid and pore tortuosity. Additionally, the performance difference among these materials and catalyst layers can be explained by the larger average pore size for Pt black CLs, since molecular $\mathrm{O}_{2}$ diffusion in the CL under PEFC operation conditions becomes more efficient at pore diameters $>100 \mathrm{~nm}$ particularly at high current density, whereas the less efficient Knudsen diffusion prevails at pore diameters $<100 \mathrm{~nm} .^{51}$ The structural modification of $\mathrm{Pt}_{3} \mathrm{Ni}$ aerogel CLs by adding the $\mathrm{K}_{2} \mathrm{CO}_{3}$ filler could influence on the PSDs, tortuosities and cell performances.

Modeling the effect of the $\mathrm{K}_{2} \mathrm{CO}_{3}$ filler on the catalyst layer structure and PEFC performance.-Fig. 6 shows the modeling procedure for catalyst layers of $\mathrm{Pt}_{3} \mathrm{Ni}$ aerogel plus $\mathrm{K}_{2} \mathrm{CO}_{3}$, assuming that $\mathrm{K}_{2} \mathrm{CO}_{3}$ either forms a thin layer on the $\mathrm{Pt}_{3} \mathrm{Ni}$ aerogel surface or affects the size of agglomerates in the catalyst ink (see Experimental section for details). The former "thin film model" is illustrated in the top row, whereby $\mathrm{Pt}_{3} \mathrm{Ni}$ agglomerates coated with $2 \mathrm{~nm}$ thick $\mathrm{K}_{2} \mathrm{CO}_{3}$ film (blue) were accumulated in the same way as in the previous study. Subsequently, the $\mathrm{K}_{2} \mathrm{CO}_{3}$ film was removed to simulate the acid washing step, while preserving the $\mathrm{Pt}_{3} \mathrm{Ni}$ aerogel structure. The procedure concluded by an ionomer coating step, again analogous to the study in the first part. In the latter "huge agglomerate model", huge bar agglomerates consisting of 10 bar agglomerates were formed first, followed by the accumulation and ionomer coating steps.

Fig. 7 shows the 3D reconstruction and cross-section images of the real CL from $\mathrm{Pt}_{3} \mathrm{Ni}$ aerogel plus $\mathrm{K}_{2} \mathrm{CO}_{3}$ and the CLs derived from

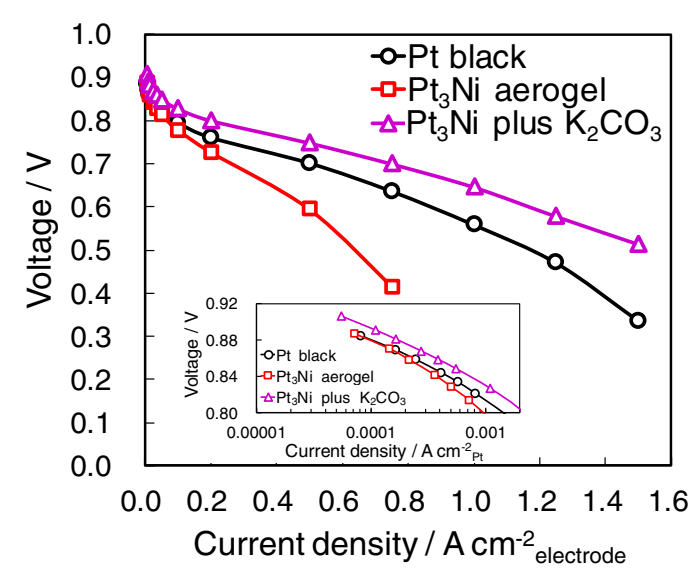

Figure 5. i-V curves and Tafel plots of the corresponding MEAs. 
Case 1: $\mathrm{K}_{2} \mathrm{CO}_{3}$ thin film model (TFM)

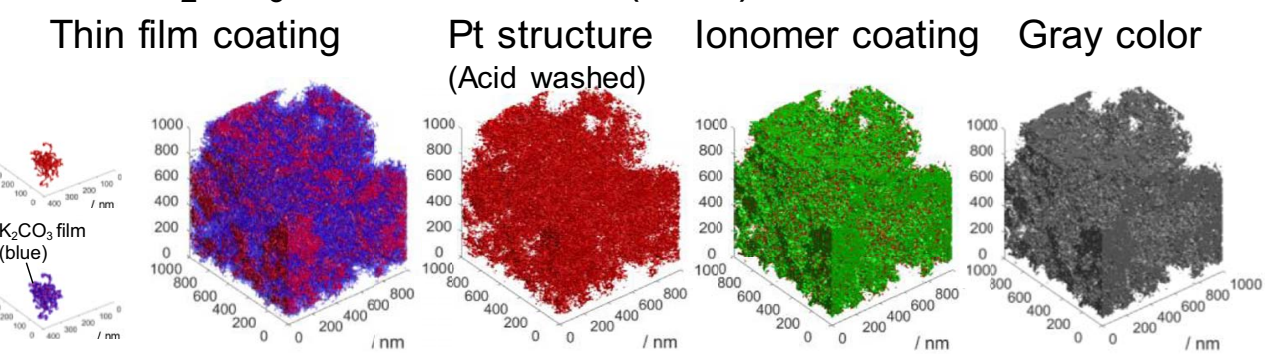

Case 2: $\mathrm{Pt}_{3} \mathrm{Ni}$ huge agglomerate model (HAM) Huge agglomerates Pt structure lonomer coating
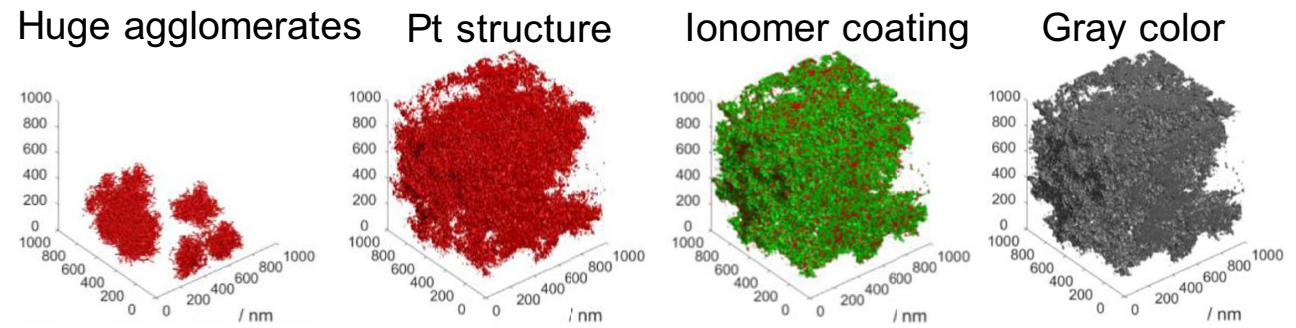

Figure 6. Case studies of the model CLs simulating $\mathrm{Pt}_{3} \mathrm{Ni}$ plus $\mathrm{K}_{2} \mathrm{CO}_{3}$.

the TFM and HAM models. The real CL using $\mathrm{Pt}_{3} \mathrm{Ni}$ aerogel plus $\mathrm{K}_{2} \mathrm{CO}_{3}$ exhibits an increased proportion of large pores $(>100 \mathrm{~nm})$ when compared to the one without $\mathrm{K}_{2} \mathrm{CO}_{3}$, as the comparison of Figs. $3 \mathrm{~F}$ and $7 \mathrm{D}$ illustrates. This trend is also discernable from the PSDs in Fig. 8A, although the overall porosities of the CLs were almost the same $(\approx 60 \%$, cf. Table I). Furthermore, both pore and solid tortuosity of the $\mathrm{CL}$ decreased by introducing $\mathrm{K}_{2} \mathrm{CO}_{3}$ (Fig. 8B). These results indicate that the $\mathrm{K}_{2} \mathrm{CO}_{3}$ filler induces the formation of large pores and enhances the pore connectivity which, as discussed above, could improve $\mathrm{O}_{2}$ mass transport within the CL. The latter hypothesis is

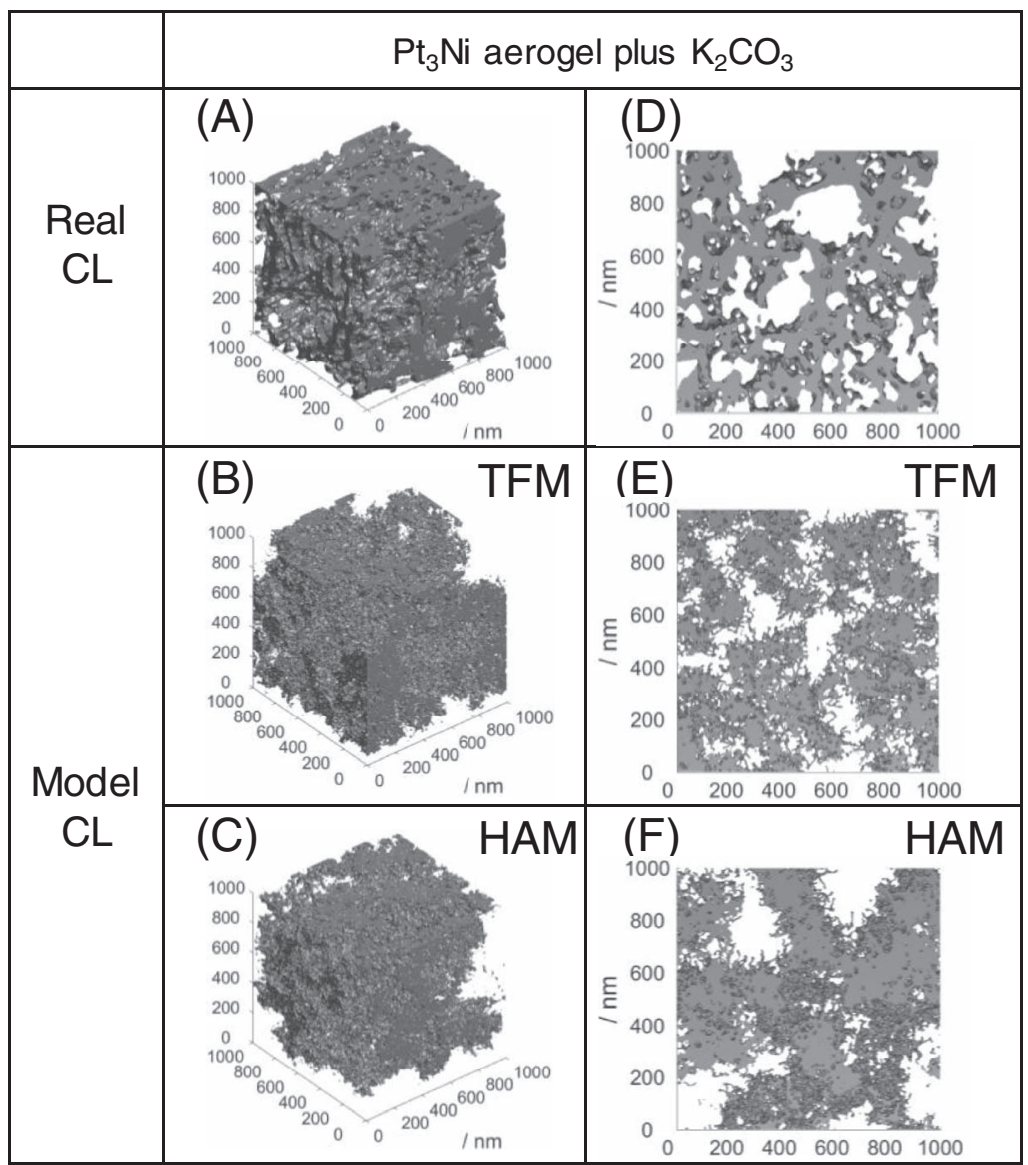

Figure 7. Real CL structures of $\mathrm{Pt}_{3} \mathrm{Ni}$ aerogel plus $\mathrm{K}_{2} \mathrm{CO}_{3}(\mathrm{~A})$ and model CL structures constructed as case studies of TFM (B) and HAM $(\mathrm{C})$, and the cross-sectional images of each CL (D,E,F). 
(A)
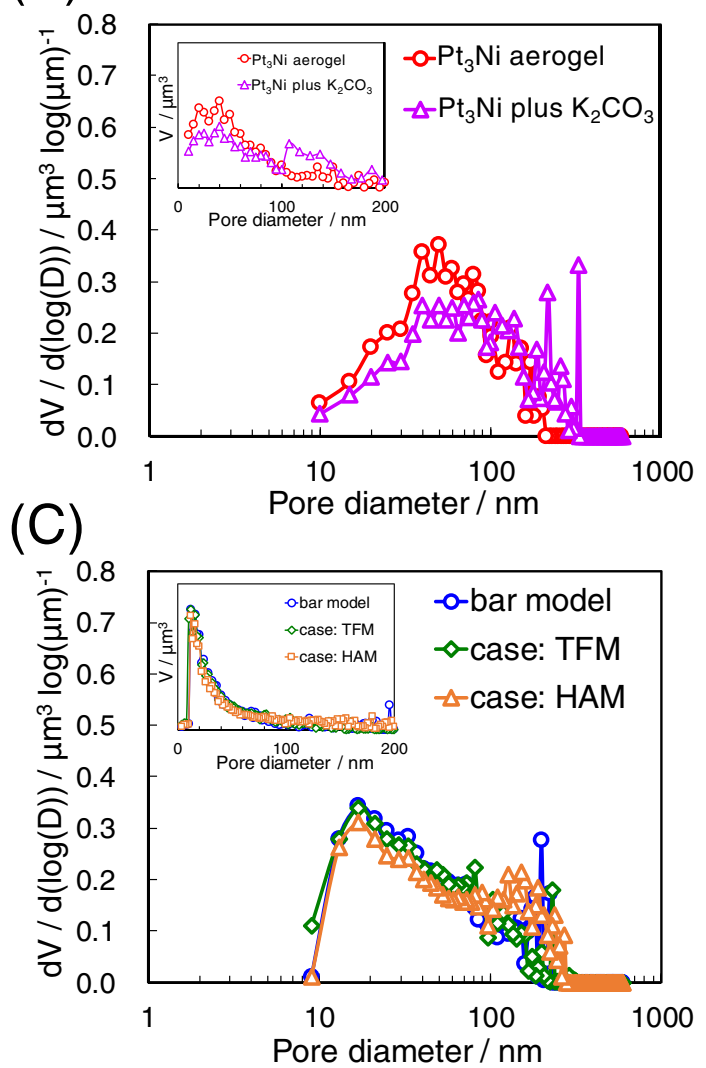
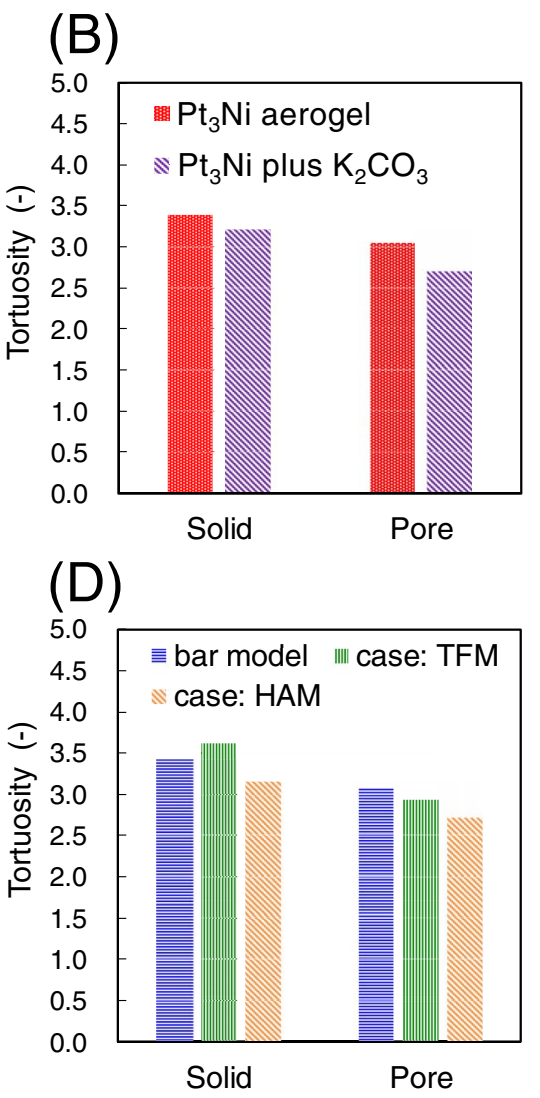

Figure 8. PSDs and tortuosities of the real CL (A,B) consisting of $\mathrm{Pt}_{3} \mathrm{Ni}$ aerogel plus $\mathrm{K}_{2} \mathrm{CO}_{3}$ and the model CLs (C,D) in case studies.

again experimentally supported by the drastic improvement in the high current density performance displayed by the $\mathrm{CL}$ of $\mathrm{Pt}_{3} \mathrm{Ni} \mathrm{CL}$ with $\mathrm{K}_{2} \mathrm{CO}_{3}$ when compared to the behavior observed in the absence of the carbonate (see red vs. purple lines in Fig. 5). The additional enhancement of the electrochemical surface area and in the kinetic region (cf. Table II) was discussed in detail in Reference 26 and is related to the improvement of Pt utilization and effectiveness ${ }^{52}$ in the optimized catalyst layer.

Interestingly, the high current density performance in fuel cell experiments increases with decreasing pore tortuosity for all investigated samples, i.e. $\mathrm{Pt}_{3} \mathrm{Ni}<\mathrm{Pt}$ black $<\mathrm{Pt}_{3} \mathrm{Ni}$ plus $\mathrm{K}_{2} \mathrm{CO}_{3}$ (see Figs. 5, 4B and $8 \mathrm{~B}$ ).

As for the model CLs, the HAM resulted in an increased number of large pores $(>100 \mathrm{~nm}$ ) with respect to the bar model (mimicking the carbonate-free $\mathrm{Pt}_{3} \mathrm{Ni} \mathrm{CL}$ ), which agrees well with the trends observed for the real CLs (Figs. 8A vs. 8C). The 3D structure and the cross-section image of the HAM model point at the steric hindrance between bar agglomerates as the reason for the formation of larger pores. Additionally, both pore and solid tortuosity in the HAM case were lower than those in the bar model, which again agrees with the tortuosity trends of the real CLs (Figs. 8B and 8D).

In contrast to this similarity, the PSD in the TFM case was rather similar to the original bar model (Fig. 8C), although the pore tortuosity

Table II. Electrochemical surface areas (ECSAs) at $25^{\circ} \mathrm{C}$ and surface-specific ORR activities (SAs) at $0.9 \mathrm{~V}\left(\mathrm{H}_{2} / \mathrm{O}_{2}, 100 \% \mathrm{RH}\right.$, $80^{\circ} \mathrm{C}, 1.5 \mathrm{bar}_{\mathrm{abs}}$ ) for the MEAs in Figure 5.

\begin{tabular}{cccc} 
& Pt black & $\mathrm{Pt}_{3} \mathrm{Ni}$ & $\mathrm{Pt}_{3} \mathrm{Ni}$ plus $\mathrm{K}_{2} \mathrm{CO}_{3}$ \\
\hline ECSA $\left(\mathrm{m}^{2} / \mathrm{g}_{\mathrm{Pt}}\right)$ & 16 & 23 & 30 \\
$\mathrm{SA}\left(\mathrm{mA} / \mathrm{cm}^{2}{ }_{\mathrm{Pt}}\right)$ & 0.17 & 0.14 & 0.28
\end{tabular}

decreased and the solid tortuosity increased as compared to the bar model. This behavior can be explained by the removal of the $\mathrm{K}_{2} \mathrm{CO}_{3}$ thin film, which leaves behind small and connected pores between the agglomerates, but has little influence on the overall PSDs. Ultimately, due to the reduction in pore tortuosity, it is assumed that the $\mathrm{O}_{2}$ diffusivity in both HAM and TFM CLs is higher than in the case of the simple, carbonate-free bar model. Nevertheless, HAM seems to be in closer agreement with the PSD and tortuosity data of the real $\mathrm{Pt}_{3} \mathrm{Ni}$ aerogel plus $\mathrm{K}_{2} \mathrm{CO}_{3} \mathrm{CL}$. Thus, the carbonate's mode of action during the real CL preparation process could potentially extend beyond a mere role as a filling material, i.e. it could also affect the ink properties during the spraying, e.g. by increasing the average agglomerate size.

To summarize these findings, Fig. 9 displays cross sections and schematic representations of the four model CLs studied in this work. The ball model CL (Figs. 9A and 9E) preponderantly exhibits large pores (>100 nm wide), while the bar model (Figs. 9B and 9F) yields predominantly small pores $(<100 \mathrm{~nm})$ placed both within and between the individual bar agglomerates. Additionally, the latter bar model features greater pore and solid tortuosity values that appear to be related to the high aspect ratio of the individual bar aggregates. The modeled tortuosities and PSDs were in good agreement with the values obtained from FIB-SEM tomography of corresponding real CLs of Pt black (ball-type model) and $\mathrm{Pt}_{3} \mathrm{Ni}$ aerogel (bar-type model). As anticipated from the lower pore tortuosity and larger average pore size, Pt black CLs showed more efficient $\mathrm{O}_{2}$ mass transport, in agreement with their high current density behavior upon recording of $\mathrm{H}_{2}$ /air polarization curves (Fig. 5).

Moreover, the effect of a filler material on the bar-type model $\left(\mathrm{Pt}_{3} \mathrm{Ni} \mathrm{CL}\right)$ was simulated assuming a thin film and a huge agglomerate scenario. The former TFM CL (Figs. 9C, 9G) could form small and connected pores by removing $\mathrm{K}_{2} \mathrm{CO}_{3}$ resulting in lower pore tortuosity. The latter HAM CL (Figs. 9D and 9H) displays significantly more and larger pores than the basic bar model, and was able to pre- 
(A)

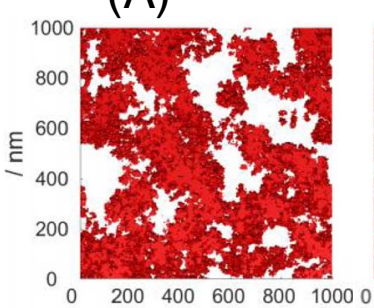

(C)

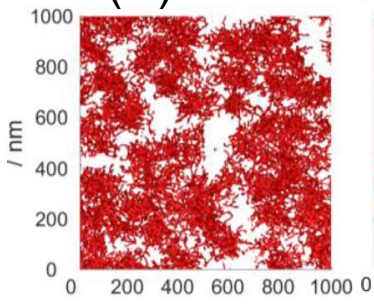

(B)

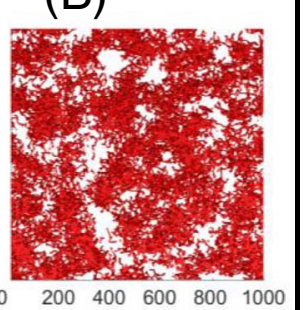

(D)

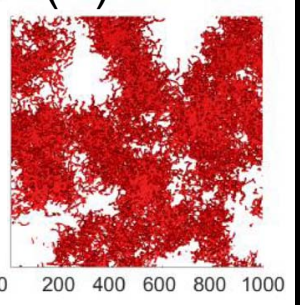

(E)

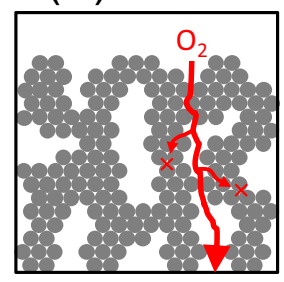

(G)

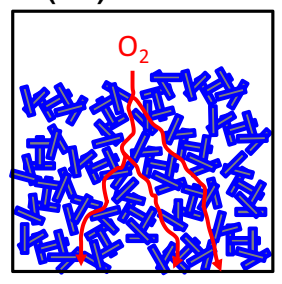

( $\mathrm{F})$

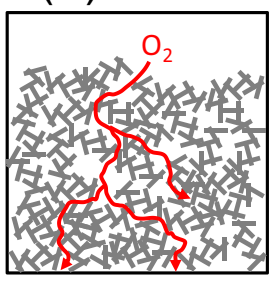

$(\mathrm{H})$

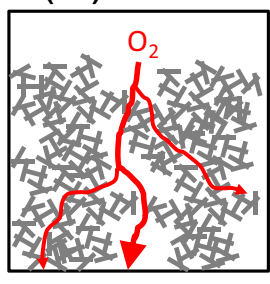

Figure 9. Cross sections and schematic representations of CL structures from ball model $(\mathrm{A}, \mathrm{E})$, bar model $(\mathrm{B}, \mathrm{F})$, TFM (C,G) and HAM $(\mathrm{D}, \mathrm{H})$ and suggested $\mathrm{O}_{2}$ diffusion pathways. dict the structural changes of the real $\mathrm{CL}$ upon $\mathrm{K}_{2} \mathrm{CO}_{3}$ addition. Thus the HAM CL forms both large and small pores and is associated with efficient $\mathrm{O}_{2}$ diffusion which is consistent with the higher cell voltage at large current densities observed in the $\mathrm{H}_{2}$ /air polarization curve of the respective $\mathrm{Pt}_{3} \mathrm{Ni}$ aerogel plus $\mathrm{K}_{2} \mathrm{CO}_{3} \mathrm{CL}$ (Fig. 5).

In the future work, by conducting the coupled analysis of computational fluid dynamics (CFD) and electrochemical reaction in the CL, the CL structure and the cell performance will be correlated quantitatively. Furthermore, more structural variables (e.g. the size and shape of the agglomerates, material compositions and the amount of filler material) could be modified and optimized and the results would be fed back to the experimental CL design. The modeling techniques used herein can also be applied for investigating the effect of degradation after durability tests (cf. particle coalescence observed in Reference 53 after load-cycling) by discussing the influences of the CL structural change on the cell performance.

\section{Conclusions}

The structures of real CLs from differently shaped catalysts, prepared with and without the use of a filler material, were compared to the ones obtained by a computational modeling approach that simulates the catalyst layer preparation process. Interestingly, the catalyst's shape at the nanoscale had a profound influence on the final CL structure, leading to mainly large and straight pores (>100 $\mathrm{nm}$ in width) for Pt black and mostly small and twisted pores $(<100 \mathrm{~nm}$ wide $)$ for $\mathrm{Pt}_{3} \mathrm{Ni}$ aerogel. In this respect, the developed modeling approach proved very accurate in predicting the 3D structure, PSDs, and tortuosities obtained for real CLs. Complementing PEFC experiments using $\mathrm{Pt}$ black and $\mathrm{Pt}_{3} \mathrm{Ni}$ aerogel CLs indicated significantly poorer $\mathrm{O}_{2}$ mass transport for the latter, highlighting the importance of shifting the pore size distribution toward larger values. This shortcoming can be mitigated by the addition of a pore precursor filler material $\left(\mathrm{K}_{2} \mathrm{CO}_{3}\right)$ to the $\mathrm{Pt}_{3} \mathrm{Ni}$ catalyst ink, whereas the working principle remained elusive so far. Applying our modeling approach, the $\mathrm{K}_{2} \mathrm{CO}_{3}$ 's influence as a filler (TFM) and ink agglomerate-increasing compound (HAM) were studied separately. While both approaches lead to a positive shift of the PSD as observed for real $\mathrm{Pt}_{3} \mathrm{Ni}$ plus $\mathrm{K}_{2} \mathrm{CO}_{3} \mathrm{CLs}$, the better agreement between the results derived with the latter HAM and the real data points at the ink agglomerate size as an important factor determining the CL structure of unsupported catalysts. Ultimately, the novel modeling approach could constitute a viable tool to facilitate the design of nanostructured catalysts by providing a first prediction of the relation between catalyst shape and $\mathrm{O}_{2}$-diffusion efficiency in the corresponding CL.

\section{Acknowledgments}

The authors thank Dr. Daniel Abbott and Dr. Elisabeth Müller for assistance with electron microscopy experiments and ScopeM (ETH Zurich) for the use of their facilities. Additional thanks goes to Dr. Gen Inoue at Kyushu University for providing programming codes of modeling and image processing. This work was funded by the Swiss National Science Foundation (20001E_151122/1), the German Research Foundation (EY 16/18-1) and the European Research Council (ERC AdG 2013 AEROCAT).

\section{ORCID}

Thomas J. Schmidt (D) https://orcid.org/0000-0002-1636-367X

\section{References}

1. M. Shao, Q. Chang, J.-P. Dodelet, and R. Chenitz, Chem. Rev., 116, 3594 (2016).

2. R. Borup, J. Meyers, B. Pivovar, Y.-S. Kim, R. Mukundan, N. Garland, D. Myers, M. Wilson, F. Garzon, D. Wood, P. Zelenay, K. More, K. Stroh, T. Zawodzinski, J. Boncella, J. E. McGrath, M. Inaba, K. Miyatake, M. Hori, K. Ota, Z. Ogumi, S. Miyata, A. Nishikata, Z. Siroma, Y. Uchimoto, K. Yasuda, K. Kimijima, and N. Iwashita, Chem. Rev., 107, 3904 (2007).

3. A. J. Appleby, Catal. Rev., 4, 211 (1970).

4. V. R. Stamenkovic, B. S. Mun, M. Arenz, K. J. J. Mayrhofer, C. A. Lucas, G. Wang, P. N. Ross, and N. M. Markovic, Nat. Mater, 6, 241 (2007).

5. A. Rabis, P. Rodriguez, and T. J. Schmidt, ACS Catal., 2, 864 (2012).

6. J. Zhang, H. Yang, J. Fang, and S. Zou, Nano Letters, 10, 638 (2010).

7. V. R. Stamenkovic, B. Fowler, B. S. Mun, G. Wang, P. N. Ross, C. A. Lucas, and N. M. Markovic, Science, 315, 493 (2007).

8. M. Li, Z. Zhao, T. Cheng, A. Fortunelli, C. Y. Chen, R. Yu, Q. Zhang, L. Gu, B. V. Merinov, Z. Lin, E. Zhu, T. Yu, Z. Jia, J. Guo, L. Zhang, W. A. Goddard III, Y. Huang, and X. Duan, Science, 354, 1414 (2016).

9. L. Castanheira, W. O. Silva, F. H. B. Lima, A. Crisci, L. Dubau, and F. Maillard, ACS Catal., 5, 2184 (2015).

10. S. Zhang, X. Yuan, H. Wang, W. Mérida, H. Zhu, J. Shen, S. Wua, and J. Zhang, Int. J. Hyd. Energy, 34, 388 (2009).

11. M. Hara, M. Lee, C.-H. Liu, B.-H. Chen, Y. Yamashita, M. Uchida, H. Uchida, and M. Watanabe, Electrochim. Acta, 70, 171 (2012).

12. Y. Shao, G. Yin, and Y. Gao, J. Pow. Sourc, 171, 558 (2007).

13. Y.-J. Wang, D. P. Wilkinson, and J. Zhang, Chem. Rev., 111, 7625 (2011).

14. Y. Chino, K. Taniguchi, Y. Senoo, K. Kakinuma, M. Hara, M. Watanabe, and M. Uchida, J. Electrochem. Soc., 162, F736 (2015).

15. T. Binninger, R. Mohamed, A. Patru, K. Waltar, E. Gericke, X. Tuaev, E. Fabbri, P. Levecque, A. Höll, and T. J. Schmidt, Chem. Mater, 29, 2831 (2017).

16. M. K. Debe, Nature, 486, 43 (2012).

17. C. Zhu, D. Du, A. Eychmüller, and Y. Lin, Chem. Rev., 115, 8896 (2015).

18. C. Koenigsmann,W.-P. Zhou, R. R. Adzic, E. Sutter, and S. S. Wong, Nano Lett., 10, 2806 (2010).

19. H. Kuroki, T. Tamaki, and T. Yamaguchi, J. Electrochem. Soc., 163, F927 (2016).

20. B. Cai, S. Henning, J. Herranz, T. J. Schmidt, and A. Eychmüller, Adv. Energy Mater, 1700548 (2017). 
21. E. Antolini and J. Perez, J. Mater. Sci., 46, 4435 (2011).

22. M. Watanabe, H. Sei, and P. Stonehart, J. Electroanal. Chem., 261, 375 (1989).

23. K. Okaya, H. Yano, H. Uchida, and M. Watanabe, ACS Appl. Mater. Interfaces, 2 888 (2010)

24. M. Lee, M. Uchida, D. A. Tryk, H. Uchida, and M. Watanabe, Electrochimica Acta, 56, 4783 (2011)

25. K. Takahashi, R. Koda, K. Kakinuma, and M. Uchida, J. Electrochem. Soc., 164 F235 (2017).

26. S. Henning, H. Ishikawa, L. Kühn, J. Herranz, E. Müller, A. Eychmüller, and T. J. Schmidt, Angew. Chem. Int. Ed., 56, 10707 (2017)

27. S. Thiele, R. Zengerle, and C. Ziegler, Nano Res., 4, 849 (2011)

28. M. Klingele, R. Zengerle, and S. Thiele, J. Pow. Sourc., 275, 852 (2015).

29. G. Inoue, K. Yokoyama, J. Ooyama, T. Terao, T. Tokunaga, N. Kubo, and M. Kawase, J. Pow. Sourc., 327, 610 (2016)

30. L. Chen, G. Wu, E. F. Holby, P. Zelenay, W.-Q. Tao, and Q. Kang, Electrochim. Acta, 158, 175 (2015).

31. A. Z. Weber, R. L. Borup, R. M. Darling, P. K. Das, T. J. Dursch, W. Gu, and D. Harvey, J. Electrochem. Soc., 161, F1254 (2014).

32. K. J. Lange, P.-C. Sui, and N. Djilali, J. Electrochem. Soc., 157, B1434 (2010).

33. P. P. Mukherjee and C. Y. Wang, J. Electrochem. Soc., 153, A840 (2006).

34. S. H. Kim and H. Pitsch, J. Electrochem. Soc., 156, B673 (2009).

35. J. Kang, K. Moriyama, and S. H. Kim, J. Pow. Sourc., 325, 752 (2016).

36. N. A. Siddique and F. Liu, Electrochim. Acta, 55, 5357 (2010).

37. G. Inoue and M. Kawase, J. Pow. Sourc., 327, 1 (2016).

38. G. Inoue and M. Kawase, Int. J. Hydrogen Energy, 41, 21352 (2016).

39. R. Kotoi, G. Inoue, and M. Kawase, ECS Trans, 75, 385 (2016).
40. S. Henning, L. Kühn, J. Herranz, J. Durst, T. Binninger, M. Nachtegaal, M. Werheid, W. Liu, M. Adam, S. Kaskel, A. Eychmüller, and T. J. Schmidt, J. Electrochem. Soc, 163, F998 (2016).

41. P. Oberholzer, P. Boillat, A. Kaestner, E. H. Lehmann, G. G. Scherer, T. J. Schmidt, and A. Wokaun, J. Electrochem. Soc., 160, F659 (2013).

42. H. A. Gasteiger, S. S. Kocha, B. Sompalli, and F. T. Wagner, Appl. Catal. B: Environ., 56, 9 (2005)

43. H. Schulenburg, B. Schwanitz, N. Linse, G. G. Scherer, A. Wokaun, J. Krbanjevic, R. Grothausmann, and I. Manke, J. Phys. Chem. C, 115, 14236 (2011).

44. M. L. -Haro, L. Guétaz, T. Printemps, A. Morin, S. Escribano, P.-H. Jouneau, P. B. -Guillemaud, F. Chandezon, and G. Gebel, Nat. Commun., 5, 5229 (2014).

45. K. L. More, R. Borup, and K. S. Reeves, ECS Trans., 3, 717 (2006).

46. H. Sugimori, T. Terao, Y. Nishino, Y. Ito, A. Miyazawa, Y. Konosu, M. Koga, H. Matsumoto, S. Uemura, Y. Kameya, T. Sasabe, T. Yoshida, K. Shinohara, and S. Hirai, ECS Trans., 80, 253 (2017).

47. G. Inoue, Y. Matsukuma, and M. Minemoto, ECS Trans., 25, 1519 (2009).

48. Y. Watanabe and Y. Nakashima, Computers \& Geosciences, 28, 583 (2002).

49. M. Watanabe, M. Tomikawa, and S. Motoo, J. Electroanal. Chem., 195, 81 (1985).

50. M. Uchida, Y.-C. Park, K. Kakinuma, H. Yano, D. A. Tryk, T. Kamino, H. Uchida, and M. Watanabe, Phys. Chem. Chem. Phys., 15, 11236 (2013).

51. N. Nonoyama, S. Okazaki, A. Z. Weber, Y. Ikogi, and T. Yoshida, J. Electrochem. Soc., 158, B416 (2011)

52. M. Lee, M. Uchida, H. Yano, D. A. Tryk, H. Uchida, and M. Watanabe, Electrochim. Acta, 55, 8504 (2010).

53. S. Henning, J. Herranz, H. Ishikawa, B. J. Kim, D. Abbott, L. Kühn, A. Eychmüller, and T. J. Schmidt, J. Electrochem. Soc., 164, F1136 (2017). 